\title{
Experimental Study on Pyrolysis Characteristics of Oily Sludge from Oil Production Plant on North China Oilfield
}

\author{
$\mathrm{Yu} \mathrm{ZHOU}$ \\ Department of Mechanical Engineering \\ Beijing Institute of Petrochemical technology \\ Beijing 102617, P.R. China

\section{Zheng CHANG*} \\ Department of Mechanical Engineering \\ Beijing Institute of Petrochemical technology \\ Beijing 102617, P.R. China \\ e-mail: changzheng@bipt.edu.cn
}

\section{Yuan LI}

Opto - Mechatronic Equipment Technology Beijing Area

Major Laboratory

Beijing Institute of Petrochemical technology

Beijing 102617, P.R. China

\author{
Zhao-quan CHEN \\ Department of Mechanical Engineering \\ Beijing Institute of Petrochemical technology \\ Beijing 102617, P.R. China
}

\author{
Yin-qi FENG \\ Opto - Mechatronic Equipment Technology Beijing Area \\ Major Laboratory \\ Beijing Institute of Petrochemical technology \\ Beijing 102617, P.R. China \\ e-mail: fengyinqi@bipt.edu.cn.
}

\begin{abstract}
With the shortage of natural resources and the increase of solid waste discharges in the world, many countries take solid wastes as "resources" for comprehensive utilization. Oily sludge, as one of the solid wastes, contains a large amount of organic matter and harmful substances, which can be paralyzed and used. Samples were collected from the bottom of a sedimentation tank at sewage treatment field on North China Oilfield. Using a microcomputer differential thermal balance, oil pyrolysis experiments on 3oily sludge samples with different oil and water contents were carried out at different heating rates. The effects of heating rate, temperature and time on pyrolysis reactions were analyzed. The activation energy and frequency factors were calculated according to experimental data. Pyrolysis kinetic equations of these sludge samples were derived as well. Using a XRY-1A oxygen bomb calorimeter, the combustion calorific values of these sludge samples were obtained through calorimetric experiments.
\end{abstract}

Keywords-Oil Sludge; Pyrolysis experiment; Pyrolysis kinetic equation; Calorific value.

\section{INTRODUCTION}

The compositions of oily sludge produced from a sewage treatment plant on North China oilfield is very complex. It is a very stable suspension emulsion fluid. Beside a large number of aging crude oil, wax, bitumen and colloid in its own composition, a lot of coagulating agents, corrosion inhibitor agents, scale inhibitors and water treatment agents are added in production processed, in which a large number of pathogenic bacteria, parasites (eggs), heavy metals, toxic and harmful substances difficult to degrade and radioactive elements are formed. Not only seriously damaged the ecological environment, but also seriously affected the normal operation of oil factories and refinery. And It restricts the implementation which is being popularized in the oil field to simplify technology transformations in old systems $[1,2]$.

Due to organic matters with high calorific value in the oil sludge, they can be processed by a pyrolysis method. And their oil and gas can also be recovered. [3,4] In this paper, pyrolysis characteristic experiments and calorific value determination experiments were carried out usin goily sludge samples from a sewage treatment field of a sewage treatment factory on North China oilfield. The effects of heating rate, temperature and time on pyrolysis reactions were analyzed.

\section{EXPERIMENTAL APPARATUS AND TEST METHOD}

Experimental instruments: a TG/DTA6300 thermogravimetric analyzer and a XRY-1A oxygen bomb calorimeter.

Thermo-gravimetric measurement system: a dish, a harness balance with ranging arms, a photoelectric sensor, a measurement amplifier with differential and integral calibration, an electromagnetic balance coil and an electric zero coil. When the balance has a slight tilt due to sample quality difference, the photoelectric sensor will produce a corresponding polarity signal which is sent to the weight amplifier which output signals are 0-5 volt signals. After $\mathrm{A} / \mathrm{D}$ conversion, it is sent into a computer drawing processing.

Experimental method: About 10mg oil sludge is put into the computer differential thermal balance instrument. Temperatures are set in the range from room temperature to $600{ }^{\circ} \mathrm{C}$, and set heating rate $10{ }^{\circ} \mathrm{C} / \mathrm{min}$. During experiments, experimental data were recorded and experimental phenomena were observed. 


\section{PYROLYSIS EXPERIMENTAL DATA}

By observing the amount of residues after pyrolysis reaction, it can be seen that sample 1 contains less oil, sample 2 is almost all oil, and sample 3 contains the least oil. The thermos-gravimetric curves of these three samples are shown in Figure 1 and Figure 2.
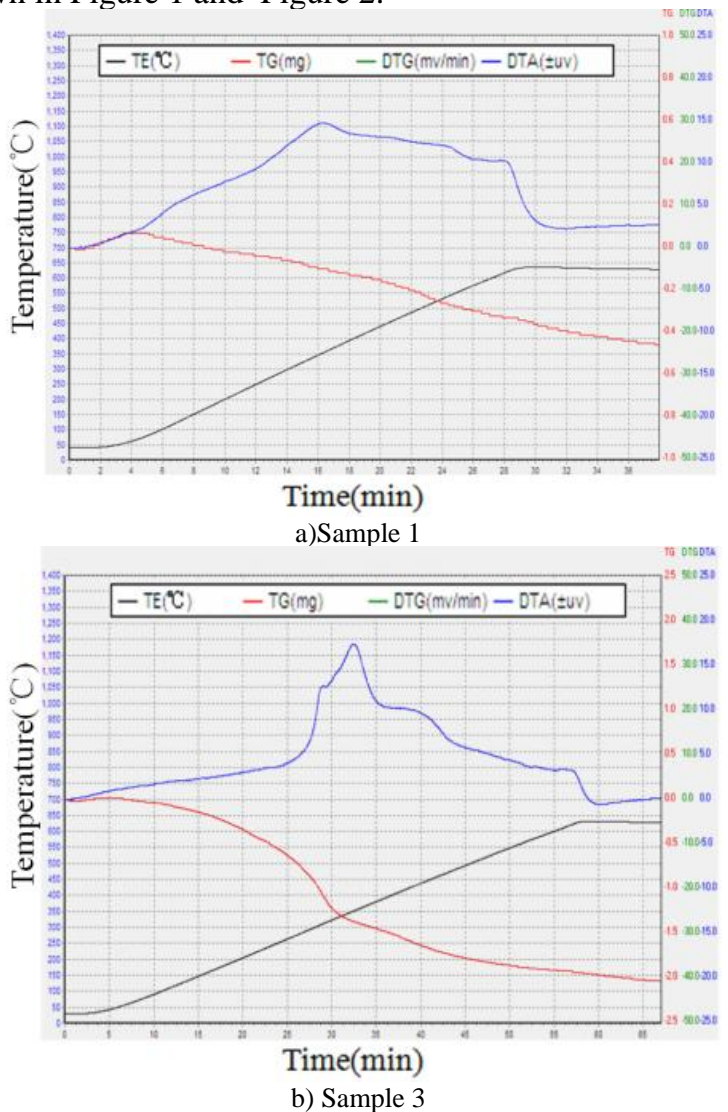

b) Sample 3

Figure 1. Thermo-gravimetric curves of samples 1 and 3

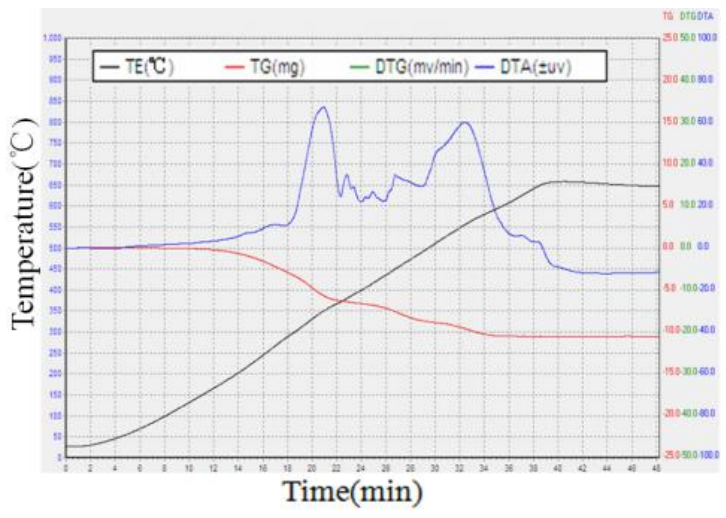

a) $15^{\circ} \mathrm{C} / \mathrm{min}$

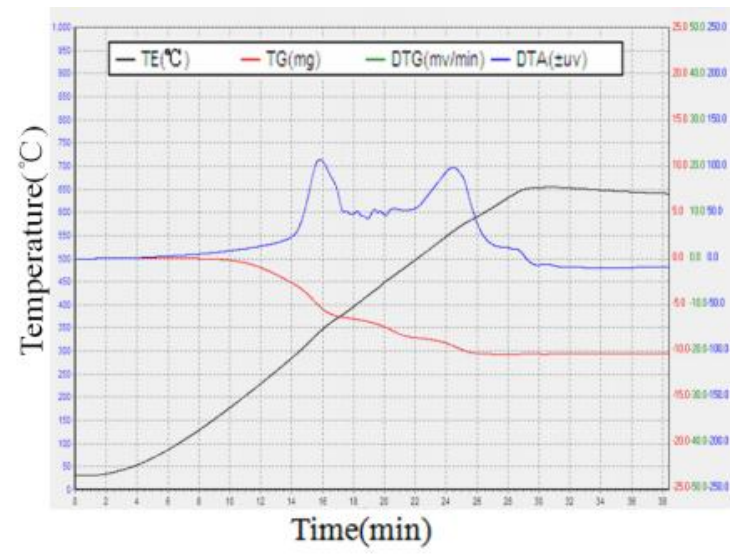

b) $20{ }^{\circ} \mathrm{C} / \mathrm{min}$

Figure 2. Thermo-gravimetric plots of sample 2

From the data of these three samples and their thermosgravimetric curves given in Fig. 1 and Fig.2, a main factor affecting oil sludge pyrolysis processes is temperature. When temperature at $200^{\circ} \mathrm{C}-400^{\circ} \mathrm{C}$ thermal decomposition efficiency is highest. The thermos-gravimetric curves of sample 2 at $15{ }^{\circ} \mathrm{C} / \mathrm{min}$ and $20{ }^{\circ} \mathrm{C} / \mathrm{min}$ were compared in Fig.2. It can be seen that two curves are nearly the same. It can be concluded that heating rates has little effect on pyrolysis processes.

\section{PYROLYSIS KINETIC EQUATIONS}

According to the literature [5] and [6], pyrolysis processes of oily sludge have the following form of pyrolysis kinetic equation:

$$
\frac{\mathrm{d}(\mathrm{TG})}{\mathrm{dT}} /\left[\mathrm{TG}_{\max }(1-\omega)^{\mathrm{n}}\right]=\exp \left(-\frac{\mathrm{E}}{\mathrm{RT}}\right) \mathrm{k}_{0} / \phi
$$

Where $\mathrm{TG}_{0}$ : weight loss of a substance before reaction (\%); TG: its weight loss when its temperature is T(\%); TG $\max$ : its weight loss after reaction $(\%)$; $\mathrm{E}$ is activation energy of the reaction, $\mathrm{R}=8.31 \mathrm{~J} / \mathrm{K}$ is a constant, $\omega$ is solid reaction rate; $\mathrm{K}_{0}$ is initial reaction rate constant; $\Phi=\mathrm{dT} / \mathrm{dt}$ is the heating rate, $\% /{ }^{\circ} \mathrm{C}$.

Parameters of pyrolysis kinetics equations of oily sludge can be easily derived from 3 samples given by Figure 1 and Figure 2.Assume that the reaction order of $n=1$, by(1)on the left, drawing its $1 / \mathrm{T}$ type, a straight line can be obtained. The slope of the straight line gives activation energy of the reaction and the frequency factor is obtained by its intercept. Pyrolysis kinetic equations of the three samples are shown in Table 1. 
TABLE I. PYROLYSIS KINETIC EQUATIONS OF THREE TEST SAMPLES

\begin{tabular}{cccc}
\hline $\begin{array}{c}\text { Experiment } \\
\text { (heating rate) }\end{array}$ & $\begin{array}{c}\text { Activation } \\
\text { energy }\end{array}$ & $\begin{array}{c}\text { Frequenc } \\
\text { y factor }\end{array}$ & Pyrolysis Kinetic equation \\
\hline Sample 1(10) & 5094.861 & 309.69 & $d \omega / d t=309.69 \exp (-613.1 / T)(1-\omega)$ \\
Sample2(15) & 8314.155 & 139.122 & $d \omega / d t=139.122 \exp (-1000.5 / T)(1-\omega)$ \\
Sample2(20) & 9021.336 & 141.067 & $d \omega / d t=141.067 \exp (-1085.6 / T)(1-\omega)$ \\
Sample3(20) & 9998.59 & 223.907 & $d \omega / d t=223.907 \exp (-1203.2 / T)(1-\omega)$ \\
\hline
\end{tabular}

\section{MAJOR CALORIFIC VALUE DETERMINATION}

Calorific values of oily sludge samples are tested using a XRY-1A oxygen bomb calorimeter. As sample 3 is difficult to contact with ignition wires because of its form and surface viscosity, it cannot be lit. Therefore, only calorific values of sample 1 and sample 2 was measured. $2.98 \mathrm{~kg}$ water was taken through the platform, and oxygen was charged in oxygen bomb until its pressure to be $2 \mathrm{MPa}$. In order to prevent incomplete combustion of samples due to the small amount of oxygen filled, which cloud result in deviations of experimental data, two samples should be taken according to their real situation. Experimental data are shown in Table 2.

\begin{tabular}{ccccc} 
TABLE II. & \multicolumn{3}{c}{$\begin{array}{c}\text { EXPERIMENTAL DATA FOR CALORIFIC VALUE } \\
\text { MEASUREMENT }\end{array}$} \\
\hline Name & $\begin{array}{c}\text { Qualit } \\
\mathbf{y}(\mathbf{k g})\end{array}$ & $\begin{array}{c}\text { Ignitio } \\
\mathbf{n} \text { wire } \\
(\mathbf{c m})\end{array}$ & $\begin{array}{c}\text { Initial } \\
\text { temperature } \\
\left({ }^{\circ} \mathbf{C}\right)\end{array}$ & $\begin{array}{c}\text { Maximum } \\
\text { temperature } \\
\left({ }^{\circ} \mathbf{C}\right)\end{array}$ \\
\hline $\begin{array}{c}\text { Sampl } \\
\text { e1 }\end{array}$ & $\begin{array}{c}0.0021 \\
1\end{array}$ & 7 & 24.238 & 25.61 \\
$\begin{array}{c}\text { Sampl } \\
\text { e2 }\end{array}$ & $\begin{array}{c}0.0004 \\
06\end{array}$ & 7 & 27.831 & 29.091 \\
\hline
\end{tabular}

Heats released by the two samples when they are completely burned are calculated using data in Table 2 and the following formula:

$$
\mathrm{Q}=\mathrm{cm} \Delta \mathrm{t}
$$

Where $\mathrm{c}$ is the specific heat capacity of water, $4200 \mathrm{~J} / \mathrm{kg}$; $\mathrm{m}$ is water quality, $\mathrm{kg} ; \Delta \mathrm{t}$ is temperature change, ${ }^{\circ} \mathrm{C}$. The calculated heats for Sample 1 and Sample 2 are Q1 = 17171.952J and Q2 $=15770.16 \mathrm{~J}$, respectively.

\section{CONCLUSION}

Using oil sludge samples from a sewage treatment plant on North China oilfield, pyrolysis experiments and calorific value determination experiments were carried out. Through the thermo-gravimetric analysis and thermal analysis following conclusions are given:

1) Oil sludge pyrolysis process can be divided into two stages. The temperature $0 \sim 200 \mathrm{oC}$ is in the first stage which is an evaporation stage where oil sludge loses water. The temperature of 200 600 degrees Celsius is in the second stage which is pyrolysis stage of the oil sludge.

2) The effect of different heating rate on thermal weight curves is not obvious, but different temperatures have a great influence on these heat curves.

3) The oil content of sample $2>$ that of sample 1 oil $>$ that of sample 3 .

4) Pyrolysis reactions of oil sludge are a first-order reaction process. The frequency factor and activation energy of three samples are calculated and their pyrolysis kinetic equations are given as shown in Table 1.

5) The calorific value of Sample 1 is 8.138365877 $\mathrm{MJ} / \mathrm{kg}$; and the calorific value of Sample 2 is 38.84275862 $\mathrm{MJ} / \mathrm{kg}$.

Experimental data mainly come from experimental instruments. As these instrument shave errors, experimental data had some deviation. However these experimental results provide the basis for designing oil sludge treatment processes and devices.

\section{ACKNOWLEDGMENT}

This work is financially supported by a 2016 grant (KM201610017001) from Science Research Development Program of Beijing Education Council, P.R. China.

\section{REFERENCES}

[1] Haoyuan Tang, Yuqi Jin, Jianhua Yan, Experimental research on oil sludge fluidized bed incineration, Power System Engineering. 24,13(2008).

[2] Roberto Fernandes, Gaspar González, Elizabete Lucas, Assessment of polymeric flocculants in oily water system, Colloid and Polymer Science. 28(2005).

[3] Jun Li, Yatian Luo, Sa Ding, Analysis on Domestic and foreign present situation of oily sludge treatment, Energy Environmental Protection. 21,12(2007).

[4] Wanfu Wang, HaoJin, Feng Shi, Peng Liu, Huang Jie, Pyrolysis Technology Overview of Oily Sludge, Chemical Engineering of Oil and Gas.39,173(2010).

[5] Shuang Chen, Qingjie Guo, Zhiqi Wang, Huie Liu, Study on pyrolysis kinetics of refinery oily sludge, Journal of China University of Petroleum(Edition of Natural Science).31,116(2007).

[6] ChunWu, Jianjun Zhou, Zhaocheng Zhao, Dongfeng Zhao, Yong Jiang, Catalytic thermal pyrolysis for recycling and disposal of oily sludge, Environmental Pollution \& Control. 10,759 (2007). 